\title{
É só sucesso! O rádio e o consumidor de baixa renda
}

\author{
Just hit! The radio and low-income consumers \\ Maria de Lourdes Bacha \\ (mlbacha@gmail.com) \\ Celso Figueiredo Neto ${ }^{2}$ \\ (kekofig@gmail.com) \\ http://dx.doi.org/10.5216/cei.v16i1.25082
}

\begin{abstract}
Resumo
Este artigo tem como objetivo principal analisar o consumo mediático de rádio através do resultado de pesquisa empírica longitudinal conduzida em São Paulo, Capital, junto a indivíduos da baixa renda (selecionados segundo o critério Brasil de classificação socioeconômica) em duas fases (2006, a amostra de 449 respondentes e 2011, amostra de 420 respondentes). As principais justificativas se referem à participação da renda baixa estimada em 78\% do total da população brasileira (CETELEM BGN, 2011) como também ao fato de que o rádio está presente em 100\% dos domicílios permanentes de São Paulo (IBGE, 2011). O tema se situa conceitualmente na sociedade de consumo tendo com base o hibridismo de culturas influenciadas pela comunicação de massa (CANCLINI, 2008). O artigo se inicia com breve revisão da literatura, seguida pela análise dos principais resultados. Os resultados indicam que o rádio é a segunda principal mídia para esta população ( $82 \%$ em 2006 , e $77 \%$ em 2011), só perdendo para a TV, além de ser considerado um bom companheiro contra a solidão e excelente fonte de informação, dispensando até a leitura de jornais.
\end{abstract}

Palavras-chave: Consumo midiático de radio. Comportamento do consumidor da baixa renda. Comunicação.

\begin{abstract}
This article aims at analyzing the media consumption of radio through the longitudinal results of empirical research conducted in Sao Paulo, Capital, with low-income population (selected by Brazil socioeconomic criterion of classification) in two phases (in 2006 with a sample of 449 respondents and in 2011 with a sample of 420 respondents). The main reasons that justify this article are related to the participation of lowincome population estimated at $78 \%$ of the total Brazilian population (BGN CETELEM, 2011) and also to the fact that radio is present in $100 \%$ of permanent households in Sao Paulo (IBGE, 2011). The theme is conceptually based on the influences of mass media on the consumer society (CANCLINI, 2008). The article begins with a brief review of the literature, followed by the analysis of the main results of the empirical research. The results indicate that the radio is the second leading media for this population ( $82 \%$ in 2006 and $77 \%$ in 2011), second only to TV. Radio is a good companion against loneliness and an excellent source of information.
\end{abstract}

Keywords: Media consumption of radio. Low income consumer behavior. Communication.

\footnotetext{
${ }^{1}$ Graduada em Administração de Empresas pela Universidade de São Paulo. Possui Pós-Doutorado, Doutorado e Mestrado em Comunicação e Semiótica pela Pontifícia Universidade Católica de São Paulo. Atualmente é Docente e pesquisadora no Centro de Comunicação e Letras da Universidade Presbiteriana Mackenzie, coordenadora de monitoria de psicologia.

${ }^{2}$ Doutorado em Comunicação e Semiótica pela PUC-SP, professor pesquisador da Universidade Presbiteriana Mackenzie, líder do grupo Pario de pesquisa, editor da revista Inovcom.
}

Comum \& Inf, v. 16, n. 1, p. 62-76, jan./jun. 2013 


\section{Introdução}

$\mathrm{E}$

ste artigo tem como objetivo principal apresentar os resultados de pesquisa empírica longitudinal conduzida em São Paulo, Capital, junto a indivíduos da baixa renda (selecionados segundo o critério Brasil de classificação socioeconômica). O tema se situa conceitualmente na sociedade de consumo tendo com base o hibridismo de culturas influenciadas pela comunicação de massa (CANCLINI, 2008).

Há várias justificativas para a escolha do tema. De um lado, a transformação da pirâmide social brasileira em losango, como resultado da política monetária e econômica, a partir do plano real, resultando na incorporação de milhões de brasileiros ao mercado de trabalho e consumo. Atualmente estima-se que a participação da renda baixa (também referida como classes socioeconômicas C e D, a partir do "critério Brasil" ou base da pirâmide) seja de $78 \%$ do total da população brasileira. Nos últimos anos, com a ascensão de aproximadamente 19 milhões de brasileiros das classes D e E para a classe C, esta passou a ser a maior do país, com mais de 101 milhões de pessoas, representando 53\% da população, percentual que deverá atingir 58\% em 2012, segundo projeções (CETELEM BGN, 2011; O ESTADO DE S. PAULO, 2011).

A evolução das tecnologias tem ampliado todos os meios de comunicação frente às opções à disposição dos consumidores, incluindo o centenário meio rádio. No passado, o rádio era limitado ao que estava disponível nas frequências AM e FM. Hoje as possibilidades de escuta se estenderam com as plataformas digitais: internet, players de mp3, celulares, satélite e rádio digital. Segundo dados do grupo de mídia (2012), a rádio AM responde por 42,1\% e a rádio FM por 57.9\% do mercado.

No Brasil há 56.640 milhões de domicílios onde o rádio está presente. Na região sudeste, 25.065 milhões de domicílios têm rádio, o que configura posse de 98\%, já em São Paulo, a posse de rádio corresponde a 100\% dos domicílios (IBGE, 2011). Com relação à penetração por classes sociais, na classe $\mathrm{C} 1$ o rádio responde por $77 \%$, a TV por $97 \%$ e na classe $\mathrm{C} 2$ o rádio tem $75 \%$ de penetração enquanto que a TV tem 98\%. Também segundo o grupo de mídia, 35\% buscam informação no rádio, 29\% ouvem rádio por entretenimento e 29\% para se distrair. Quanto ao local, $68 \%$ ouvem rádio em casa, $17 \%$ no carro, $14 \%$ no trabalho e 3\% em transporte público (GRUPO DE MÍDIA, 2012).

\section{Referencial teórico}

Comun \& Info, v. 16, n. 1, p. 67-81, jan./jun. 2013 
De acordo com Baroni e Baldo (2010), o rádio é um meio de comunicação de massa, conhecido pelo público e eficaz quanto ao alcance das informações transmitidas. É um meio que está presente no dia-a-dia das pessoas e mesmo com o crescimento da internet, percebe-se que as rádios estão disponibilizando seu conteúdo sonoro também por este meio.

A revisão da literatura mostra que há ênfase quanto à informação jornalística, mas haveria uma lacuna do ponto de vista de marketing, como veiculação de propaganda no radio. Algumas das principais características do rádio são: adentramento, intimidade (fala ao indivíduo), regionalismo, imediatismo, mobilidade, acessibilidade, custo barato, função social e comunitária. Quanto à recepção pode ser: ambiental - serve de pano de fundo; companhia - a audição acontece com atividade paralela; atenção concentrada - o ouvinte concentra sua atenção à mensagem e seleção intencional - o ouvinte se prepara e escolhe um programa (BARBOSA FILHO, 2003).

Para Ortiwano (1985), o que vem à mente ao se pensar em radio como veículo é uso da linguagem oral, penetração, mobilidade, baixo custo de produção, imediatismo, instantaneidade e autonomia, mas, principalmente, sensorialidade. Seria através da sensorialidade do rádio conquista e envolve o ouvinte, um diálogo mental entre o emissor e o receptor. O rádio desperta a imaginação através da emocionalidade das palavras e dos recursos de sonoplastia, permitindo que as mensagens tenham nuances individuais, de acordo com as expectativas de cada um. Comparando com a TV, a decodificação das mensagens também se dá ao nível sensorial, só que a imaginação é limitada pela presença da imagem. No caso dos veículos impressos, a sensorialidade está muito mais contida, permitindo a decodificação racional, sem envolvimentos emocionais que são criados pela presença da voz (ORTRIWANO, 1985, p. 80).

$\mathrm{O}$ rádio, no sentido de estímulo à fantasia seria superior à televisão. $\mathrm{O}$ rádio, para milhões de brasileiros, representou - e para outros tantos ainda representa - um meio de exercitar a imaginação e a sensibilidade (PIRES, 2002, p.36).

Uma das vantagens do rádio é ser uma mídia barata, tanto para quem produz quanto para quem adquire a tecnologia de recepção e que chega a muitos lugares do país. Do ponto de vista da recepção, o rádio tem um alcance maior do que os impressos porque ao ouvinte basta ter a capacidade de ouvir (não ser surdo) para captar a mensagem; não é exigida alfabetização (como no jornal impresso). Mesmo na televisão existem informações transmitidas por escrito que podem fugir à capacidade do telespectador analfabeto. $\mathrm{O}$ rádio permite mobilidade tanto do emissor (produção em estúdio ou externas de diversas naturezas), quanto do receptor (rádios portáteis que possibilitam a audição na rua, no carro, nos diversos cômodos da casa etc.). É um veículo de comunicação 
imediata: os fatos podem ser transmitidos no instante em que ocorrem (instantâneo e efêmero); a mensagem é recebida no momento em que é emitida, se o ouvinte não estiver exposto ao meio naquele instante, a mensagem não o atingirá (assim como na TV, neste ponto os impressos levam vantagem) (BARONI; BALDO 2010).

No Brasil, o idealizador do rádio foi Edgar Roquette-Pinto, em 1922, ao perceber sua importância como forma de comunicação popular. Roquette-Pinto costumava dizer:

O rádio é a escola dos que não têm escola. É o jornal de quem não sabe ler; é o mestre de quem não pode ir à escola; é o divertimento gratuito do pobre; é o animador de novas esperanças, o consolador dos enfermos e o guia dos sãos - desde que o realizem com espírito altruísta e elevado (ESCOLA BRASIL, 2013, s/p).

De acordo com modesto e guerra (2010), o início das transmissões radiofônicas no Brasil foi marcado pelo amadorismo e desconhecimento da linguagem do meio. Em seus primórdios, não havia roteiro. No entanto, este cenário foi mudando. Nesse sentido, a linguagem que foi sendo desenvolvida para o rádio começou a incorporar mais e mais recursos narrativos de oralidade, contação de história, música e trilhas sonoras que enriqueciam as narrativas, tornando o veículo cada vez mais interessante para ouvintes de todos os estratos sociais.

O decreto 21.111 de $1^{\circ}$ de março de 1932 regula as atividades radiofônicas e traz, em seu artigo 73, a autorização para veiculação de publicidade, restrita a $10 \%$ do tempo total de transmissão, o que permitiu a profissionalização da atividade. É bastante curioso conforme pode ser verificado a seguir:

Art. 73. Durante a execução dos programas é permitida a propaganda comercial, por meio de dissertações proferidas de maneira concisa, clara e conveniente à apreciação dos ouvintes, observadas as seguintes condições:

A) o tempo destinado ao conjunto dessas dissertações não poderá ser superior a dez por cento $(10 \%)$ do tempo total de irradiação de cada programa;

B) cada dissertação durará, no máximo, trinta (30) segundos;

C) as dissertações deverão ser intercaladas nos programas, de sorte a não se sucederem imediatamente;

D) não será permitida, na execução dessas dissertações, a reiteração de palavras ou conceitos. (CÂMARA DOS DEPUTADOS - LEGISLAÇÃO)

$\mathrm{O}$ rádio foi o primeiro veículo de massa do século $\mathrm{XX}$, capaz de contribuir para a formação da identidade nacional e pertencimento, principalmente porque o rádio está presente em quase todos os lares brasileiros, mesmo nas regiões mais distantes (MODESTO; GUERRA, 2010). Nesse contexto, para Canclini (2008, p. 129), “o rádio e o cinema contribuíram, na primeira metade do 
século XX, para organizar os relatos de identidade e o sentido de cidadania nas sociedades nacionais".

Conforme Martín-Barbero (1987) o rádio e o cinema tornaram possível a emergência e a difusão de nova linguagem e de novo discurso social: o popular massivo.

O radio teve sua relação com a cultura mediada por um projeto estatal de modernização político, mas, também, cultural, assim, a identidade nacional forjada nos anos 40 e 50 de Getúlio a Juscelino deve muito ao rádio. As cantoras da rádio nacional do rio de janeiro pautaram moda e comportamento para milhares de moças e rapazes que as adoravam, no mesmo modo que hoje se vê ocorrer com atores de TV. Também na música, samba, choro, baião e a invenção da bossa nova se configuram como momentos seminais da construção da identidade nacional por meio do rádio (ORTRIWANO, 2002-2003).

No entanto, o rádio brasileiro nasceu como um veículo da elite; era caro naquela época. Os receptores ocupavam um lugar central na sala de estar, onde a família se reunia para ouvir músicas eruditas e radionovelas (parecido com o que veio a acontecer com a televisão posteriormente). Com a possibilidade de tornar-se economicamente viável, pela venda de publicidade, o rádio passou a produzir programação de interesse dos ouvintes de a partir do constante barateamento do custo dos receptores de rádio, mais e mais brasileiros puderam adquirir e gozar das benesses desse meio de comunicação. O meio rádio que hoje habita os fones de ouvido das pessoas nas ruas, os aparelhos de som nos carros e dos ainda resistentes receptores domésticos não nasceu popular, ou melhor, massivo (MOREIRA, 2002). Vale lembrar que a Copa do Mundo de 1938 foi a primeira transmitida ao vivo, via rádio. Antes os apaixonados torcedores ficavam sabendo apenas dos resultados dos jogos pelos jornais, que os recebiam por telégrafo. Mas os lances das partidas só podiam ser acompanhados semanas depois, quando o compacto dos jogos era exibido nos cinemas.

Do ponto de vista comercial, também o rádio passou a significar avanço nas comunicações, tanto do ponto de vista da criação de modelos comerciais (jingle, spots, apresentação, mençãoslogan, patrocínio) até a importância do meio enquanto persuasor por estar muito próximo do consumidor e em contato com ele por várias horas no dia. Apesar de ter sua morte anunciada em função das novas tecnologias, o rádio ganhou aliados como o telefone celular, o ipod, o mp4 e o tablet. Dados de setembro de 2012 mostram que pessoas entre 12 e 75 anos, 8\%, ou 4,2 milhões, escutaram rádio pela internet, percentual que atinge $11 \%$ entre jovens de 12 a 24 anos (SLAVIERO, 2012). 


\section{Pesquisa empírica: procedimentos metodológicos}

Foi realizada pesquisa empírica quantitativa, longitudinal junto a uma amostra não probabilística por conveniência (MALHOTRA, 2001), constituída de duas fases. Na primeira fase foram entrevistados 449 (2006) e na segunda fase 420 (2011) indivíduos das classes C, D residentes em São Paulo, selecionados em pontos de fluxo, usando o critério de classificação socioeconômica Brasil, relacionado ao poder de compra de indivíduos e famílias urbanas, baseada nas questões: patrimônio, bens duráveis e não duráveis, domicílio, grau de instrução do chefe de família, e outras inseridas nas classes determinadas (ABEP, 2003).

O levantamento dos dados utilizou a abordagem da entrevista pessoal, por meio de questionário estruturado aplicado por pesquisadores da empresa Visio Pesquisa e Consultoria Ltda. As entrevistas foram realizadas, em pontos de fluxo de pedestres, por bairros paulistanos com maiores concentrações de população baixa renda. As respostas dos questionários foram digitadas em máscaras de software de pesquisa SPSS.

\section{Análise e discussão dos principais resultados}

\section{Perfil da amostra}

A tabela 1 apresenta uma descrição do perfil das duas amostras estudadas segundo gênero, classificação socioeconômica, faixa etária, escolaridade. Em suma pode ser observado que as amostras são equitativamente distribuídas entre homens e mulheres e há predominância de respondentes da classe $\mathrm{c}$, que atualmente representa mais da metade da população brasileira. Vale ressaltar que algumas discrepâncias entre as duas amostras podem ser creditadas ao método de amostragem não probabilístico por conveniência.

Tabela 1 - Perfil demográfico da amostra

\begin{tabular}{l|l|l}
\hline Perfil da amostra & $\begin{array}{l}\mathbf{2 0 0 6} \\
\text { N=449 }\end{array}$ & $\begin{array}{l}\mathbf{2 0 1 1} \\
\mathbf{N}=\mathbf{4 2 0}\end{array}$ \\
\hline Sexo & $\%$ & $\%$ \\
\hline Feminino & 55 & 57 \\
\hline Masculino & 45 & 43 \\
\hline Classe socioeconômica & $\%$ & \\
\hline C & 66 & 73 \\
\hline D & 34 & 27 \\
\hline Faixa etária & $\%$ & $\%$ \\
\hline Até 15 anos & 3 & 8 \\
\hline
\end{tabular}

Comun \& Info, v. 16, n. 1, p. 67-81, jan./jun. 2013 


\begin{tabular}{l|l|l}
\hline 16 a 24 anos & 26 & 15 \\
\hline 25 a 29 anos & 22 & 18 \\
\hline 30 a 39 anos & 26 & 16 \\
\hline 40 a 49 anos & 13 & 22 \\
\hline 50 a 60 anos & 6 & 12 \\
\hline Acima de 60 anos & 3 & 7 \\
\hline Escolaridade & $\%$ & $\%$ \\
\hline Até ensino fundamental incompletgnte: & aufqres & 30 \\
\hline Até ensino fundamental completo & 20 & 21 \\
\hline Até ensino médio incompleto & 28 & 20 \\
\hline Até superior incompleto & 31 & 24 \\
\hline Superior completo. & 10 & 5 \\
\hline
\end{tabular}

participação do rádio entre as mídias tradicionais

Este item apresenta um panorama geral do que as pessoas realizam com o apoio de mídia tradicional: "assistir TV” (97\% em 2006 e 94\% em 2011), “ouvir rádio" (82\% em 2006 e 77\% em 2011), “assistir vídeos e/ou DVD” (95\% em 2006 e 66\% em 2011), "ler revistas” (36\% em 2006 e 28\% em 2011), "ler jornais" (28\% em 2006 e 26\% em 2011).

Tabela 2 - Atividades de lazer com mídias tradicionais

\begin{tabular}{lll}
\hline Atividades de lazer com mídias tradicionais & $\mathbf{2 0 0 6}$ & $\mathbf{2 0 1 1}$ \\
& $\mathbf{\%}$ & $\mathbf{\%}$ \\
\hline Assistir TV & 97 & 94 \\
Ouvir rádio & 82 & 77 \\
Assistir vídeos e/ou DVD & 95 & 66 \\
Ler revistas & 36 & 28 \\
Ler jornais & 28 & 26 \\
\hline
\end{tabular}

Fonte: autores

\section{Rádio: programas preferidos}

Inicialmente vale lembrar que ouvir rádio é uma das atividades mais frequentes, conforme tabelas anteriores. Os tipos de programas de rádio mais ouvidos são: música popular/ sucessos (62\% em 2006 e 71\% em 2011), programas sertanejos (15\% em 2006 e 31\% em 2011), variedades (33\% em 2006 e 22\% em 2011). Em segundo lugar aparecem programas religiosos (10\% em 2006 e $20 \%$ 2011), transmissão de esportes/de jogos (23\% em 2006 e 18\% em 2011), noticiários jornalísticos (18\% em 2006 e 17\% em 2011), e horóscopos (23\% em 2006 e 14\% em 2011).

Comun \& Info, v. 16, n. 1, p. 67-81, jan./jun. 2013 
Durante algum tempo, o rádio foi sinônimo quase que exclusivamente de música. Principalmente para as emissoras fm. Porém, tal realidade vem sendo alterada com o avanço tecnológico. Segundo Kischinhevsky (2009), o rádio deixou de ser alvo do fetiche de consumidores e teve sua imagem desvinculada da música. Com o advento da TV, o rádio perdeu espaço publicitário para este novo veículo. Desde sua fundação, o rádio participou de todos os momentos da vida do brasileiro. No Brasil, a partir dos anos 80 , principalmente nos grandes centros urbanos surgiu uma programação baseada no tripé música-esporte-notícia. Gêneros e formatos diferenciados foram sendo experimentados. Entre as várias especializações, no jornalismo surgiram as rádios all news (apenas notícias), e as talk \& news (com notícias, entrevistas e comentários).

Tabela 3 - Tipos de programas de rádio mais ouvidos

\begin{tabular}{lll}
\hline Tipos de programas de rádio mais ouvidos & $\mathbf{2 0 0 6}$ & $\mathbf{2 0 1 1}$ \\
& $\mathbf{\%}$ & $\mathbf{\%}$ \\
\hline Música popular/sucessos & 62 & 71 \\
Programas sertanejos & 15 & 31 \\
Variedades & 33 & 22 \\
Humor & - & 22 \\
Programas religiosos & 10 & 20 \\
Transmissão de esportes/de jogos & 23 & 18 \\
Noticiários jornalísticos & 18 & 17 \\
Horóscopos & 23 & 14 \\
Comentários/ entrevistas & 22 & 10 \\
Noticiários policiais & 8 & 8 \\
Música clássica & 14 & 7 \\
\hline
\end{tabular}

Fonte: autores

\section{Período em que costuma ouvir rádio}

O período do dia preferido para ouvir rádio é o da noite (52\% em 2006 e 47\% em 2011), contra 30\% em 2006 e 31\% em 2011 do período matutino e 19\% em 2006 e $22 \%$ do período da tarde, conforme tabela 4. AM representa 97\% e FM tem 100\% da audiência. Baroni e Baldo (2010), quanto à penetração do rádio em alguns horários, verificaram que até o meio dia, este meio de comunicação só perde em contato / audiência para o jornal, o que significa que, mesmo possuindo uma verba normalmente menor do que outras mídias em um planejamento de campanha, o rádio oferece um retorno significativo para os anunciantes.

Comun \& Info, v. 16, n. 1, p. 67-81, jan./jun. 2013 
Uma novidade significativa da tomada de dados de 2011 é a inclusão do humor como opção de tipo de programação ouvida. O humor no rádio não é novidade. Gerações de humoristas surgiram, ou inspiraram-se no irreverente humor da Prk-30. Renha (2013) conta que: "a Prk-30 permaneceu no ar por mais de vinte anos de sucesso: de 1946 a 1966 e, segundo algumas das maiores autoridades do assunto no país como Chico Anysio, Jô Soares, Renato Murce e o ex-vicepresidente da Rede Globo De Televisão, José Bonifácio Sobrinho, o Boni, foi o melhor programa de humor de todos os tempos" (RENHA, 2013, p.87-88).

Esse humor irreverente, escrachado, provocativo e frequentemente rico em polissemias de conotação sensual, é uma construção do rádio brasileiro que se proliferou outras mídias, como a TV, dando à luz a programas populares como os de Chico Anysio, Jô Soares, a Praça é Nossa, Tom Cavalcante e atualmente o Pânico, nascido na Rádio Jovem Pan e com grande audiência na televisão.

Os programas religiosos, por sua vez, também obtiveram um crescimento relevante entre as duas tomadas de dados. Contribuíram para isso a popularização da música gospel e as espetacularização da cerimônia religiosa, tornando-a num evento midiático grandioso para milhares de fiéis que, em catarse coletiva, oram e cantam. Essa emoção, além, é claro dos onipresentes sermões, são matéria perfeita para veiculação em rádio, já que prescindem da imagem, uma vez que a voz, a palavra é a grande protagonista desse tipo de programa.

Tabela 4 - Período em que costuma ouvir rádio

\begin{tabular}{l|l|l}
\hline Período em que costuma ouvir rádio & $\begin{array}{l}\mathbf{2 0 0 6} \\
\mathbf{\%}\end{array}$ & $\begin{array}{l}\mathbf{2 0 1 1} \\
\mathbf{\%}\end{array}$ \\
\hline Noite & $\mathbf{5 2}$ & $\mathbf{4 7}$ \\
\hline Manhã & 30 & $\mathbf{3 1}$ \\
\hline Tarde & 19 & $\mathbf{2 2}$ \\
\hline
\end{tabular}

Fonte: autores

\section{Atitudes com relação veículos TV, rádio e jornal}

Com relação às atitudes com relação aos veículos TV, rádio e jornal, verifica-se que a TV e o rádio são companheiros contra a solidão. "a televisão me faz sentir menos sozinho "(63\%)," o rádio é um grande companheiro para mim" (60\%). Como fonte de informação, a TV e o rádio fornecem as informações consideradas necessárias por este público alvo, corroborando os dados de

Comun \& Info, v. 16, n. 1, p. 67-81, jan./jun. 2013 
alta frequência com que assistem TV e rádio, em detrimento da leitura de jornais e revistas. "as notícias de rádio me deixam muito bem informado sobre tudo que está acontecendo no Brasil e no mundo" (65\%); "pessoas que não costumam ler jornal ou revista ficam desatualizadas muito depressa" (62\%), “os noticiários de televisão evitam que a gente tenha que ler jornal” (56\%), “eu só leio jornal porque sinto que eu preciso estar atualizado" (38\%).

Tabela 5 - Atitudes com relação aos veículos TV, rádio e jornal

\begin{tabular}{l|l}
\hline Atitudes com relação aos veículos $\boldsymbol{T V}$, rádio e jornal & $\begin{array}{l}2011 \\
\text { Grau de } \\
\text { concordância } \\
\%\end{array}$ \\
\hline Contra solidão & 63 \\
\hline A televisão me faz sentir menos sozinho & 60 \\
\hline O rádio é um grande companheiro para mim & 65 \\
\hline Fonte de informação & 62 \\
\hline $\begin{array}{l}\text { As notícias de rádio me deixam muito bem informado sobre } \\
\text { tudo que está acontecendo no brasil e no mundo }\end{array}$ & 56 \\
\hline $\begin{array}{l}\text { Pessoas que não costumam ler jornal ou revista ficam } \\
\text { desatualizadas muito depressa }\end{array}$ & 38 \\
\hline $\begin{array}{l}\text { Os noticiários de televisão evitam que a gente tenha que ler } \\
\text { jornal }\end{array}$ & 56 \\
\hline Eu só leio jornal porque sinto que eu preciso estar atualizado & 62 \\
\hline
\end{tabular}

Fonte: autores

\section{Considerações finais}

Para Canclini (1993, p. 24), o consumo de mídia é uma das formas de consumo cultural, este definido "o conjunto de processos socioculturais nos quais se realizam a apropriação e os usos dos produtos". O consumo de produtos midiáticos pode propiciar inclusão, pertencimento e cidadania, através do compartilhamento de diferentes maneiras de consumir os bens materiais e simbólicos. Essa questão é muito importante no caso da baixa renda, composta por indivíduos que possuem acesso limitado aos produtos e limitações quanto ao uso de novas tecnologias, porque apesar do progresso econômico verificado nos últimos anos, a sociedade brasileira ainda é muito desigual, o país ainda está entre os 12 mais desiguais, segundo pesquisa da FGV (DURÃO, 2012). 
O surgimento e a popularização da internet afetam diretamente o rádio e seu futuro. $\mathrm{Na}$ medida em que as rádios conseguirem acompanhar a velocidade das mudanças de comportamento dos seus ouvintes, será possível estabelecer um novo vínculo. O rádio está na sua maturidade, mas alguns autores acreditam que com a internet ele possa acrescentar e amplificar seu poder, gerando sinergia entre a rádio e a audiência, porque pode envolver estreitamente os ouvintes com ações específicas e particulares de cada segmento. Herschmann e Kischinhevsky (2008, p. 104) lembram que a reconfiguração das indústrias do rádio e da música causa impacto direto sobre o campo da cultura, mesmo antes da convergência digital, o rádio já havia ganhado mais um poderoso inimigo: as TVS por assinatura (a cabo ou via satélite), que oferecem canais de áudios estereofônicos digitais 24 horas por dia e sem comerciais.

O futuro do rádio ainda é incerto. O rádio digital, que era tido como o sucessor da atual tecnologia, está desacreditado. De acordo com ferrareto (2000), no brasil, alguns empresários investiram em novos equipamentos, fazendo com que as emissoras obtivessem som estéreo digital, porém os ouvintes, sem receptores adequados a essa novidade, nem perceberam a mudança e o formato foi deixado de lado.

No entanto, segundo o grupo de mídia de São Paulo (2012), as condições têm sido favoráveis para o rádio, que teve um crescimento na participação do bolo publicitário, o que pode ser creditado à própria mudança de comportamento da sociedade. As pessoas estão cada vez mais nas ruas e, portanto, expostas a mídias móveis, que acompanhem esse ritmo, como é o caso do rádio, a competência para desenvolver um trabalho de caráter mais proporcional; o processo de formação das redes iniciado há alguns anos e cada dia mais consolidado.

Para o mercado publicitário, trata-se de um excelente caminho, na medida em que melhora significativamente as condições em termos de custos absolutos. Pode-se destacar também que: $83 \%$ dos veículos no Brasil possuem rádio e nos últimos anos a audiência média do rádio cresceu $44 \%$.

No Brasil, o crescimento do acesso às plataformas digitais está provocando impacto nas formas de consumo de mídia. Na amostra estudada, $58 \%$ têm desktop no domicilio, $21 \%$ tem notebook no domicilio, o tempo médio diário de navegação na internet da amostra entrevistada é de 2,5 horas e $67 \%$ acessam internet de casa. Consideram-se expert em internet (4\%), conhecem bastante (17\%) e tem conhecimento médio (34\%). Além disso, $24 \%$ já fizeram compras pela internet. $\mathrm{O}$ que se pode concluir é que o futuro do rádio parece promissor frente ao crescente processo de convergência entre sistemas de comunicação e tecnologias da informação e redes

Comun \& Info, v. 16, n. 1, p. 67-81, jan./jun. 2013 
integradas de alta capacidade que carregam informação em formato digital e a emergência de diversos dispositivos e plataformas para se ouvir áudio.

A evolução da tecnologia tem ampliado radicalmente todos os meios de comunicação frente às opções à disposição dos consumidores, incluindo o centenário meio rádio. No passado, o rádio era limitado ao que estava disponível nas frequências AM e FM. Hoje as possibilidades de escuta se estenderam com as plataformas digitais: internet, players de $\mathrm{mp} 3$, celulares, satélite e rádio digital. Essa expansão tem sido mais significativa por meio da internet para o meio rádio e pode ser significativa para a baixa renda face aos dados comentados anteriormente, apesar das limitações decorrentes da escolha do método de amostragem, não probabilística que não permite generalizações para o total do universo. Considerando que o radio está presente em $100 \%$ dos domicílios, ainda parece subutilizado pelas empresas como veículo de comunicação de massas.

Não obstante as inúmeras opções de acesso a música que a internet trouxe, e que já está disponível para população de baixa renda, verifica-se que o rádio ainda é uma mídia muito utilizada. Essa escolha por uma programação não individualizada denota algumas questões que são da maior importância quando se trata dos movimentos culturais e suas relações com as mídias.

Um primeiro fator a ser observado é a grande preferência expressa pela população pesquisada pelas rádios musicais que tocam sucessos. Essa questão pode ser observada por meio de dois vieses, um demonstrando a ainda muito forte presença de sistemas massificados de comunicação. Não obstante a infinita variedade de programações musicais disponíveis para esses ouvintes a escolha de rádios de sucesso indicia uma dependência significativa das novidades da indústria cultural ainda dentro do paradigma da Escola de Frankfurt. Não deixa de ser surpreendente que, diante da imensa liberdade de escolha dos dias de hoje, grande parte da população opte pelo sistema estruturado das gravadoras e rádios de sucesso. Outra característica que pode ser deduzida dessa preferência massiva pelas rádios de sucesso é uma espécie de demanda social existente, na qual o cidadão precisa estar na moda, ciente das novidades, sabendo os refrões das novas canções, os artistas de sucessos, as novas músicas que tocam nas rádios. Essa ansiedade para acompanhar a moda indicia a dependência do sistema para saber o que é bom, jovem, moderno, socialmente adequado.

Outra questão que o presente trabalho faz aflorar é a grande audiência no horário noturno. Tanto isso quanto o fato das escolhas recaírem na programação musical, e não na jornalística expressam a decadência da importância do rádio enquanto plataforma jornalística. Tradicionalmente, o rádio sempre teve suas maiores audiências no período matutino, com os jornais

Comun \& Info, v. 16, n. 1, p. 67-81, jan./jun. 2013 
falados que remontam aos primórdios da atividade. Em São Paulo são tradicionais os jornais das Rádios Eldorado, Band e Jovem Pan. Contudo essa população acostumada a se informar sobre as novidades pelo rádio parece estar sendo substituída por outro grupo de ouvintes que prefere ouvir o rádio no período noturno. Talvez se possa afirmar que essa mudança signifique um aprofundamento da migração da função do rádio de veículo de informação para veículo de entretenimento. Além da música, o futebol cuja maioria dos jogos ocorre no período noturno continua a ser transmitido pelo rádio.

O rádio oferece, também, uma combinação de informação simples e decodificada, de fácil consumo que, entremeada de músicas (novas e sucessos) compõem um quadro significativo do universo cultural do ouvinte de baixa renda. Com algumas horas de audiência ele pode ficar sabendo os resultados do futebol, como comentários sobre os lances mais relevantes, saber as notícias mais importantes já decodificadas e simplificadas, e ouvir as músicas que estão na moda de forma a aparecer para seus pares como alguém atualizado e dinâmico.

Quase cem anos depois de sua criação, o rádio sobrevive às inovações tecnológicas que em vários momentos ameaçaram suprimi-lo e, ao mesmo tempo, encontra novos espaços entretendo e informando a população.

Artigo submetido em 26/06/2013 e aceito em 18/08/2013.

\section{Referências}

BARBOSA FILHO, A. Gêneros radiofônicos. São Paulo: Paulinas, 2003.

BARBOSA, G.G.; RABAÇA, C.A. Dicionário de comunicação. São Paulo: Ática, 2005.

BARONI, D.; BALDO, R. O rádio, veículo de comunicação de massa e para a massa. In: INTERCOM - SOCIEDADE BRASILEIRA DE ESTUDOS INTERDISCIPLINARES DA COMUNICAÇÃO, 33., 2010, Caxias do Sul. Anais do Congresso Brasileiro de Ciências da Comunicação. Caxias do Sul: Intercom Caxias, 2010.

CÂMARA DOS DEPUTADOS. Legislação. Disponível em: <http://www2.camara.leg.br/legin/fed/ decret/1930-1939/decreto-21111-1-marco-1932-498282-publicacaooriginal-81840-pe.html>. Acesso em: jun. 2013.

CANCLINI, N.G. Consumidores e cidadãos: conflitos multiculturais da globalização. 7. ed. Rio de Janeiro: UFRJ, 2008. 
DURÃO, M. Desigualdade cai pelo $11^{\circ}$ ano consecutivo. Estadão.com.br, São Paulo, 08 mar. 2012. Jornal da tarde. Disponível em: <http://blogs.estadao.com.br/jt-seu-bolso/desigualdade-caipelo-11\%C2\%BA-ano-consecutivo/>. Acesso em: jul. 2012.

ESCOLA Brasil. Disponível em: 〈http://www.escolabrasil.org.br/escola-brasil/o-radio-que-educa>. Acesso em: abr. 2013.

MODESTO, C. F. Rádio para quem? Dos ideais educativos de roquette-pinto às mãos dos políticos brasileiros: quase 90 anos de história. In: CONGRESSO DE CIÊNCIAS DA COMUNICAÇÃO NA REGIÃO SUDESTE, 14., 2009, Rio de janeiro. Anais... Rio de Janeiro, 2009.

GRUPO de mídia. Disponível em: <http://midiadados.digitalpages.com.br/html/shelf/119>. Acesso em: 23 ago. 2012.

IBGE, 2011. Disponível em: <http://seriesestatisticas.ibge.gov.br/series.aspx ?vcodigo=pd281\&t= domicilios-particulares-permanentes-por-posse-de-r\%C3\%A1dio>. Acesso em: 23 ago. 2012.

KISCHINHEVSKY, M. O rádio sem onda: convergência digital e novos desafios na radiodifusão. Rio de Janeiro: E-papers, 2007.

MARTÍN-BARBERO, J. Dos meios às mediações. 2. ed. Rio de Janeiro: UFRJ, 2003.

MODESTO, C. F.; GUERRA, M. O. A construção da identidade através das narrativas radiofônicas. In: CONGRESSO DE CIÊNCIAS DA COMUNICAÇÃO NA REGIÃO SUDESTE, 15., 2010, Vitória, ES. Anais do Intercom Vitória, ES. Vitória, ES, 2010.

MOREIRA, S. V. Rádio em transição: tecnologias e leis nos Estados Unidos e no Brasil. Rio de Janeiro: Mil Palavras, 2002.

ORTRIWANO, G. S. A informação no rádio: os grupos de poder e a determinação dos conteúdos. São Paulo: Summus, 1985.

ORTRIWANO, G.S. Rádiojornalismo no Brasil: fragmentos de história. Revista USP, São Paulo, n. 56, p. 66-85, dez./fev. 2002-2003.

RENHA, JOÃO. A propaganda brasileira depois de Washington Olivetto. Rio de Janeiro: Puc/Rio-Leya, 2013.

SLAVIERO, D. Tendências/debates, os 90 anos do rádio brasileiro. Disponível em: <http://www1.folha.uol.com.br/opiniao/1158703-tendenciasdebates-os-90-anos-do-radiobrasileiro.shtml>. Acesso em: abr. 2013.

Comun \& Info, v. 16, n. 1, p. 67-81, jan./jun. 2013 